\title{
Detection of alterations in all three exons of the peripherin/RDS gene in Swedish patients with retinitis pigmentosa using an efficient DGGE system
}

\author{
U Ekström, V Ponjavic, S Andréasson, B Ehinger, P Nilsson-Ehle, M Abrahamson
}

\begin{abstract}
Aims-To develop a sensitive mutation screening procedure suitable for routine analysis of the peripherin/RDS gene, and to estimate the nature and prevalence of peripherin/RDS gene mutations in Swedish patients with autosomal dominant retinitis pigmentosa.

Methods-To make the method as sensitive as possible, as many as eight segments, covering the three exons and the flanking intron sequences of the peripherin/RDS gene, were analysed by denaturing gradient gel electrophoresis. A group of 38 Swedish patients with a clinical diagnosis of autosomal dominant retinitis pigmentosa were screened for mutations in the peripherin/RDS gene.

Results-Three point mutations were found in four of the patients and five polymorphisms were defined. One mutation in exon 1, R172W, has been described previously in other ethnic groups as causing a macular degeneration. Another mutation, in exon 2 and causing the substitution F211L, was found in two unrelated patients. A third mutation, resulting in the likely non-pathogenic substitution S289L, as well as a polymorphism not reported previously, was found in exon 3.

Conclusions-The screening procedure described allows detection of mutations in all of the exons, including the polymorphic $5^{\prime}$ and $3^{\prime}$ ends of the gene, and is therefore suitable for routine screening of peripherin/RDS gene defects in patients with autosomal dominant retinitis pigmentosa. The frequency of mutations found in the Swedish patient group indicates that defects in the peripherin/RDS gene might be a more common cause of autosomal dominant retinitis pigmentosa than was thought previously.

(F Clin Pathol: Mol Pathol 1998;51:287-291)
\end{abstract}

Keywords: mutation; polymorphism; retina; full field electroretinography

Retinitis pigmentosa is a heterogeneous entity with constriction of the visual fields, moderate reduction of visual acuity, and pigmentation of the retina as the common features; these characteristics have been the main diagnostic criteria in the past. The overall incidence of retinitis pigmentosa is about one in 4000 , without any apparent ethnic or racial differences. ${ }^{1}$ Retinitis pigmentosa unassociated with other abnormalities is inherited as an autosomal dominant, as an autosomal recessive or, less frequently, as an X-linked recessive disease. In recent years, multiple different defects in the genes encoding a number of photoreceptor associated proteins have been reported for patients with retinitis pigmentosa, including rhodopsin, ${ }^{2}$ peripherin/RDS, ${ }^{3}{ }^{4} \mathrm{ROM}-1,{ }^{5} \operatorname{rod} \mathrm{PDE}-\beta,{ }^{6} \mathrm{rod}$ cGMP gated channel, ${ }^{7}$ and rod PDE-a, ${ }^{8}$ displaying the heterogeneity of the molecular basis for the disease.

In our study, we have examined 38 Swedish patients with the clinical diagnosis of autosomal dominant retinitis pigmentosa, looking for sequence variations in the peripherin/RDS gene. We used denaturing gradient gel electrophoresis (DGGE) analysis ${ }^{9}$ of polymerase chain reaction (PCR) amplified DNA fragments, ${ }^{10}$ which contained a 40 base pair (bp) long GC clamp at one end, ${ }^{11}$ and covered all three exons and flanking intron sequences of the peripherin/RDS gene. The sensitivity of the screening procedure was optimised by dividing the three exons of the gene into eight fragments according to the MELT87 computer algorithm (kindly supplied by L Lerman and W Fripp, Cambridge, Massachusetts, USA).

Material and methods

SUBJECTS

Thirty eight patients from the department of ophthalmology were included in our study. The patients were diagnosed clinically as having retinitis pigmentosa, and family history indicated that the disease was inherited. The ophthalmological examination included visual acuity, ophthalmoscopy, slit lamp examination, and fundus photography. Visual field testing was performed with Goldmann kinetic perimetry and the final dark adapted rod thresholds were obtained with a Goldmann-Weeker adaptometer.

ELECTRORETINOGRAPHY

Full field electroretinograms were recorded in a Nicolet Compact Four analysis system (Nicolet Biomedical Instruments, Madison, Wisconsin, USA), as described previously. ${ }^{12}$ Both eyes were tested after maximal pupil dilatation with topical $10 \%$ phenylephrine hydrochloride and $1 \%$ cyclopentolate hydrochloride, and after 40 minutes of dark adaptation. A Burian-Allen bipolar contact lens electroretinogram electrode was applied on the topically anaesthetised cornea, together with a 
Table 1 Primers and conditions for PCR and DGGE of peripherin/RDS exon fragments

\begin{tabular}{|c|c|c|c|c|}
\hline Fragment & Primer & Oligonucleotide sequence ( $5^{\prime}$ to $\left.3^{\prime}\right)$ & $\begin{array}{l}\text { PCR annealing } \\
\text { temperature }\end{array}$ & $D G G E(\%)$ \\
\hline \multirow[t]{2}{*}{$\overline{1 \mathrm{~A}}$} & UE171 & GTT TGG GGT GGG AGC TGT GC & $63^{\circ} \mathrm{C}$ & $50-70 \%$ \\
\hline & UE172 & GC-AG TTG GGC ACA AAA TGG CTC TC & & \\
\hline \multirow[t]{2}{*}{$1 \mathrm{~B}$} & UE173 & GC-TT CCT GAA GAT TGA ACT CCG AAA GA & $63^{\circ} \mathrm{C}$ & $50-70 \%$ \\
\hline & UE174 & GCA GAG AGC CAC AAG GAA GAG & & \\
\hline \multirow[t]{2}{*}{$1 \mathrm{C}$} & UE175 & GC-CT GAA GCC GTA CCT GGC TAT C & $63^{\circ} \mathrm{C}$ & $50-70 \%$ \\
\hline & UE176 & GTG TCC CGG TAG TAC TTC ATG C & & \\
\hline \multirow[t]{2}{*}{$1 \mathrm{D}$} & UE177 & GCT CGC TGG AGA ACA CCC TG & $63^{\circ} \mathrm{C}$ & $50-70 \%$ \\
\hline & UE178 & GC-CC CCA ATA TAT TCA TAG CTC TGA C & & \\
\hline \multirow[t]{2}{*}{$2 \mathrm{~A}$} & UE179 & GC-GG GAA GCC CAT CTC CAG CTG T & $60^{\circ} \mathrm{C}$ & $50-75 \%$ \\
\hline & UE180 & TGG TGA TCT GAT ACT GGA TGC AG & & \\
\hline \multirow[t]{2}{*}{$2 \mathrm{~B}$} & UE181 & GC-TC CCT TTC AGC TGC TGC AAT C & $63^{\circ} \mathrm{C}$ & $50-75 \%$ \\
\hline & UE182 & GGA GGC TCT CCT TAC ССТ CTA & & \\
\hline \multirow[t]{2}{*}{$3 \mathrm{~A}$} & UE183 & GC-CT CCC AGC GAT TCT CCC AGA T & $60^{\circ} \mathrm{C}$ & $50-75 \%$ \\
\hline & UE184 & GGC ACG CTC TTC TCC AGC AG & & \\
\hline \multirow[t]{2}{*}{$3 \mathrm{~B}$} & UE185 & GC-TG GAT GGT GTG TCC AAC CCC & $63^{\circ} \mathrm{C}$ & $65-90 \%$ \\
\hline & UE186 & GAG TGC ACT ATT TCT CAG TGT TC & & \\
\hline
\end{tabular}

For each fragment, the nucleotide sequence of the primers used, the PCR annealing temperature, and the DDGE gradient used for analysis are given.

GC-, GC clamp (GCG CCG CGC CCG TCC CGC CGC CGC CCG CCG CCG GCG CCC G).

ground electrode on the forehead. Responses were obtained with a wide band filter $(3 \mathrm{~dB}$ at $1 \mathrm{~Hz}$ and $500 \mathrm{~Hz})$, stimulating with single, full field flashes (100 $\mu$ second) with dim blue light (Wratten filters numbers $47,47 \mathrm{~A}$, and $47 \mathrm{~B}$ combined; $25 \mathrm{~cd} / \mathrm{m}^{2}$ ), and with white light $\left(7500 \mathrm{~cd} / \mathrm{m}^{2}\right)\left(0.75 \mathrm{~cd} \cdot\right.$ second $\left./ \mathrm{m}^{2}\right)$. Cone responses were obtained with $30 \mathrm{~Hz}$ flickering white light $\left(7500 \mathrm{~cd} / \mathrm{m}^{2}\right)$ averaged from 20 sweeps. The referred luminances of the three different light stimuli were measured on the light reflected from the Ganzfeld sphere.

MUTATION SCREENING

Blood samples from the subjects were collected in tubes containing ethylenediaminetetra acetic

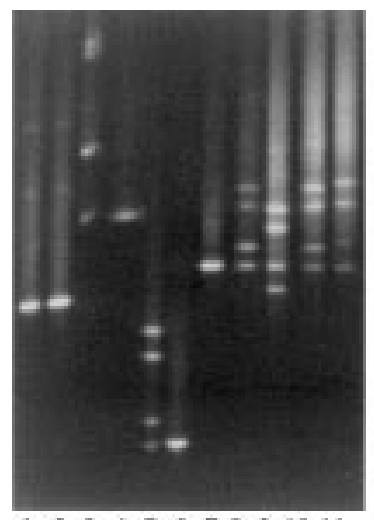

1234567891011

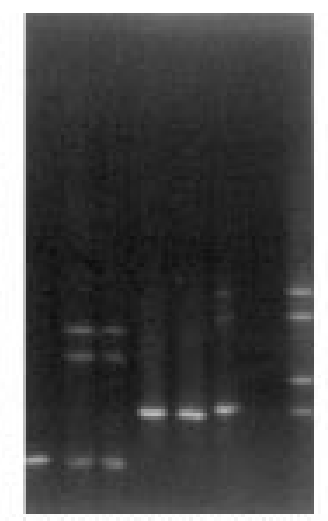

$121314 \quad 1516 \quad 17 \quad 18 \quad 19$

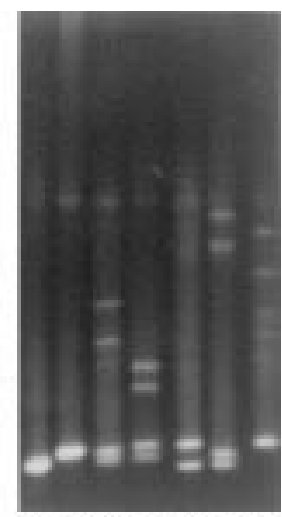

20212223242526
Figure 1 DGGE patterns. The amplified GC clamped fragments were analysed on a gel with a denaturating gradient ranging from 50\% to 90\% denaturant (100\% denaturant is $7 \mathrm{M}$ urea and $40 \%$ (vol/vol) deionised formamide), depending on the the screened fragment. Electrophoresis was carried out for 22 hours. The gels were stained with ethidium bromide and the band patterns visualised by UV light. The photographs are from three different gel runs with different denaturing gradients: lanes 1-11, 50-70\%; lanes 12-19, $50-75 \%$; and lanes 20-26, 65-95\%. A sequence alteration gives rise to additional bands compared with the single band that is seen for the wild-type homoduplex in the

electropherogram. In the description below, fragments with mutations are denominated with the resulting amino acid substitution in the case of control DNA samples with known mutations or, in the case of the patient DNA samples analysed in our study, by patient number. Exon $1 \mathrm{~A}$ (promotor, codon 55), lanes 1 and 2: wt (wild-type fragments). Exon $1 B$ (codons 49-111): lane 3, poly (fragments with polymorphisms); lane 4, wt. Exon $1 C$ (codons 105-136): lane 5, poly; lane 6, wt. Exon $1 D$ (codon 131, intron 1): lane 7, wt; lane 8, RP13; lane 9, L185P; lane 10, R172W; lane 11, R172Q. Exon $2 A$ (intron 1, codon 220): lane 12, wt; lane 13, RP6; lane 14, RP37. Exon 2B (codon 217, intron 2): lane 15, wt; lane 16, wt. Exon $3 A$ (intron 2, codon 306): lane 17, poly; lane 18, empty; lane 19, RP27. Exon 3B (codon 297-3' non-translated region), seven different genotypes - different combinations of four polymorphisms in fragment $3 B$ (in codons 304,310 , and 338 , and in the 3' non-translated region (nucleotide 13), respectively): lane 20, RP6 (E/E304, K/K310, G/G338, C/C); lane 21, RP2 (E/E304, K/K310, G/G338, T/T); lane 22, RP11 (Q/E304, K/K310, D/G338, C/C); lane 23, RP8 (E/E304, K/K310, G/G338, C/T); lane 24, RP14 (Q/E304, R/K310, D/G338, C/T); lane 25, RP13 (Q/E304, R/K310, D/G338, C/C); lane 26, RP7 (Q/E304, K/K310, D/G338, C/T). acid (EDTA) as anticoagulant and genomic DNA was isolated from the leucocyte fraction. ${ }^{13}$ Melting maps of PCR fragments corresponding to each of the three exons of the peripherin/RDS gene with a $40 \mathrm{bp}$ GC clamp attached to either the 5'-end or the 3'-end of the fragments were calculated using the MELT87 computer algorithm. Because of exon length and composition, exon 1 was divided into four overlapping fragments (denominated $1 \mathrm{~A}-\mathrm{D}$ ) and exons 2 and 3 were divided into two overlapping fragments each (2A and B, $3 \mathrm{~A}$ and $\mathrm{B}$, respectively). The design of the primers used was based on the genomic exon 1,2, and 3 sequences deposited in the EMBL database (entries U07147-9). To optimise detection of splice site mutations, the primers were constructed so that at least $15 \mathrm{bp}$ of the flanking intron sequences were included in the amplified fragments. PCR was performed in a thermal cycler (Perkin Elmer-Cetus, Norwalk, Connecticut, USA) using reagents in the GeneAmp PCR reagent kit (Perkin ElmerCetus). Amplification was performed using one minute denaturation at $95^{\circ} \mathrm{C}$, one minute annealing, and one minute extension at $72^{\circ} \mathrm{C}$, repeated for 32 cycles. The cycles were preceded by five minutes denaturation at $95^{\circ} \mathrm{C}$ and followed by a six minute extension at $72^{\circ} \mathrm{C}$. Table 1 gives annealing temperatures and the sequences of the primer pairs used.

DGGE was performed on dedicated equipment from CBS Scientific Co (Del Mar, California, USA) according to the protocol described by Myers et al. ${ }^{9}$ The amplified GC clamped fragments were analysed on a gel with a denaturating gradient ranging from $50 \%$ to $90 \%$ denaturant $100 \%$ denaturant is $7 \mathrm{M}$ urea and $40 \%$ (vol $/ \mathrm{vol}$ ) deionised formamide), with the exact range depending on the fragment screened (table 1). The buffer temperature was $60^{\circ} \mathrm{C}$. Electrophoresis was carried out for 22 hours at $100 \mathrm{~V}(5 \mathrm{~V} / \mathrm{cm})$. The gels were stained with ethidium bromide $(3 \mathrm{mg} / \mathrm{ml})$ and the band patterns visualised by UV light.

PCR fragments indicated by DGGE to contain sequence alterations were sequenced using the dideoxy chain termination method. ${ }^{14}$ Fragments for sequencing were prepared by PCR of the indicated fragment according to the PCR 
Table 2 Sequence alterations found in patients with autosomal dominant retinitis pigmentosa

\begin{tabular}{|c|c|c|c|c|c|}
\hline Identity & Type & nt change & Protein change & Location & Comments \\
\hline \multicolumn{6}{|c|}{ Disease causing mutations } \\
\hline RP13 & Missense R172W & $\mathrm{C} \rightarrow \mathrm{T}$ & $\operatorname{Arg} \rightarrow \operatorname{Trp}$ & Exon 1 & a \\
\hline RP6 & Missense F211L & $\mathrm{C} \rightarrow \mathrm{G}$ & Phe $\rightarrow$ Leu & Exon 2 & b \\
\hline $\mathrm{RP} 37$ & Missense F211L & $\mathrm{C} \rightarrow \mathrm{G}$ & Phe $\rightarrow$ Leu & Exon 2 & $\mathrm{~b}$ \\
\hline \multicolumn{6}{|c|}{ Sequence alteration of unclear significance } \\
\hline RP27 & Missense S289L & $\mathrm{C} \rightarrow \mathrm{T}$ & Ser $\rightarrow$ Leu & Exon 3 & Novel $^{\mathrm{c}}$ \\
\hline \multicolumn{6}{|c|}{ Polymorphisms } \\
\hline V106V & & $\mathrm{C} \rightarrow \mathrm{T}$ & None & Exon 1 & d \\
\hline E304Q & & $\mathrm{G} \rightarrow \mathrm{C}$ & $\mathrm{Glu} \rightarrow \mathrm{Gln}$ & Exon 3 & e \\
\hline $\mathrm{K} 310 \mathrm{R}$ & & $\mathrm{A} \rightarrow \mathrm{G}$ & Lys $\rightarrow$ Arg & Exon 3 & e \\
\hline G338D & & $\mathrm{G} \rightarrow \mathrm{A}$ & Gly $\rightarrow$ Asp & Exon 3 & e \\
\hline $3^{\prime} \mathrm{NT}, \mathrm{nt} 13$ & & $\mathrm{C} \rightarrow \mathrm{T}$ & None & Exon 3 & Novel $^{\mathrm{c}}$ (Apa I site) \\
\hline
\end{tabular}

Wroblewski et al. ${ }^{16}$

${ }^{b}$ EH Souied et al, the association for research in vision and ohpthalmology meeting, Fort Lauderdale, Florida, USA, 1995 (abstract). 'No reports found in the Medline database, as of June 1997.

${ }^{\mathrm{d}}$ Farrar et al. ${ }^{3}$

'Jordan et al. ${ }^{15}$

nt, nucleotide; 3'NT, $3^{\prime}$ non-translated region.

protocol described above. Both strands of the PCR fragments were sequenced to cover the entire sequence, and the mutations were determined by sequencing both strands. Sequence reactions were performed according to the Sequenase PCR product sequencing kit (United States Biochemical, Cleveland, Ohio, USA).

\section{Results}

The peripherin/RDS gene fragments giving aberrant band patterns on DGGE (fig 1) were analysed and divided into two groups. Identical aberrant band patterns seen on DGGE of an exon fragment from several patients was denominated a polymorphism. Such polymorphisms were also found when screening a set of 90 individuals with non-autosomal dominant retinitis pigmentosa. Table 2 gives details of the polymorphisms found, as defined by sequencing. Five different polymorphisms were detected. The four located in the coding parts of the exons have been described previously. ${ }^{315}$ The fifth polymorphism is unreported and is situated just downstream from the stop codon in exon 3, leading to a novel restriction site for Apa I. The other group of exon fragments showing aberrant patterns on DGGE, patterns unique for one or two patients but not found in the group of non-autosomal dominant retinitis

I

II

III

IV
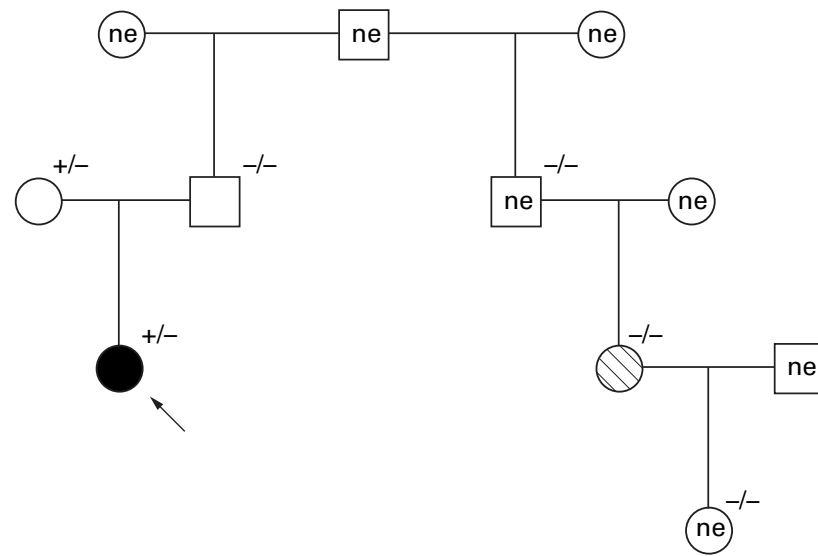

Figure 2 Pedigree for the family of patient RP27 with the S289L substitution. Circles, women; squares, men; open symbols, patients were examined and had a normal phenotype; closed symbol, patient was examined and had the retinitis pigmentosa phenotype; hatched symbol, patient was not examined but had the retinitis pigmentosa phenotype by patient history; NE, not examined and unavailable for investigation; +/-, presence or absence of the S289L mutation; the arrow indicates the index case. pigmentosa individuals, was suspected of carrying potentially disease causing mutations. Three different sequence alterations, detected in four of the 38 patients investigated, belonged to this group (table 2). The patients were heterozygous for the gene alterations.

One of the mutations, found in exon 1 of patient RP13, results in the amino acid substitution R172W, and has been described previously in at least four unrelated families. ${ }^{16-18}$ The clinical picture of this patient was that of macular degeneration.

An exon 2 mutation was found in patients from two apparently unrelated families (RP6 and RP37). This mutation gives rise to the substitution F211L, which has been detected previously, but without segregation information (EH Souied et al, the association for research in vision and ophthalmology meeting, Fort Lauderdale, Florida, USA, 1995 (abstract)). Investigation of members in three generations of one of the affected families demonstrated a co-segregation of the F211L mutation and a disease phenotype of a rather atypical form of retinitis pigmentosa. ${ }^{19}$

Another previously undescribed sequence alteration, in exon 3, was found in patient RP27, causing the substitution S289L. The patient showed a retinitis pigmentosa phenotype with typical clinical characteristics and electroretinograms demonstrated typical findings for retinitis pigmentosa. The visual field was constricted to $10^{\circ}$ with stimuli $\mathrm{I}_{4 \mathrm{e}}$ and to $20^{\circ}$ with stimuli $\mathrm{V}_{4 \mathrm{e}}$. Best corrected visual acuity was 20/30 and ophthalmoscopy revealed attenuated vessels and spicular pigmentation in all four quadrants. Final dark adapted rod thresholds were raised by at least 2-3 log units. Full field electroretinography revealed no rod responses to dim blue light and that responses to white light were greatly reduced, indicating loss of rod and cone function. The isolated cone response to $30 \mathrm{~Hz}$ flickering light was reduced and delayed. Further investigation of the patient's family showed that the mutation was present in DNA from the patient's mother, but not in that of the patient's older relative who suffered from retinitis pigmentosa (fig 2). However, the investigation also revealed that both of the patient's parents had normal vision, in spite of the initial patient history, incorrectly 
indicating dominant inheritance at the time when the patient was included in our study. Nonetheless, the substitution S289L could not be detected in any of the other 37 patients with autosomal dominant retinitis pigmentosa or in any of the 90 non-autosomal dominant retinitis pigmentosa patients who were screened. Thus, it represents an uncommon sequence alteration, which could be phenotype modulating and hence possibly affect the expression of the disease in patient RP27.

\section{Discussion}

In patients with autosomal dominant retinitis pigmentosa, several pathogenic alterations in the perpherin/RDS gene have been described. There are many reasons for analysing the occurrence of such possible mutations. Defining the gene defects of individual patients will help to elucidate the relation between the loci of the defects and the clinical expression of autosomal dominant retinitis pigmentosa. In addition, such information will be of importance for the understanding of the normal functions of the peripherin protein. Furthermore, the clinical diagnosis of autosomal dominant retinitis pigmentosa can be difficult in some patients, especially in children, who have not yet developed the characteristic criteria of the disease. In such cases, mutation analysis can be decisive for correct diagnosis, thereby achieving an early assessment of the visual handicap of the patient and the prognosis of the disease. Molecular biochemical analyses will therefore be of increasing importance.

A number of different screening approaches can be used to narrow down the gene region that needs to be sequenced to reveal a disease causing gene defect. None of the common screening methods detects every possible mutation in a given gene fragment; methods include those based on single strand conformation polymorphism analysis (SSCP), temperature gradient gel electrophoresis, the RNAase cleavage method, heteroduplex analysis, the chemical cleavage method, or DGGE. DGGE and SSCP, the two most widely used screening methods, are thought to detect more than $80 \%$ of single base pair substitutions in given fragments, ${ }^{20}{ }^{21}$ but the methods probably do not detect the same mutations if applied to the same gene material. DGGE as a screening method for detection of point mutations and other minor gene defects has proved to be helpful in the mutation screening of an array of different genes, including the peripherin/RDS gene. ${ }^{17}{ }^{22}$ In our efforts to optimise the sensitivity of the method, guided by theoretical calculations with the computer program MELT87, we divided the three exons into as many as eight overlapping DNA fragments. We also used a long DGGE run time (22 hours). We found mutations in all three exons of the gene with this optimised DGGE system. Notably, those in exons 1 and 3 were both located in the vicinity of polymorphic loci in the gene, but could still be readily distinguished by their unique and clear DGGE patterns (fig 1). In our previous analysis of DNA from the 38 patients with SSCP under standard conditions (1996, unpublished), we could only detect the exon 2 mutation, whereas using the optimised DGGE system we could detect mutations in all three exons.

Four of the 38 patients with retinitis pigmentosa included in the our study had sequence alterations in the peripherin/RDS gene. In three of these patients, the mutations are potentially disease causing for the following reasons. The R172W and F211L mutations are both located in a segment of the polypeptide chain that is thought to be located on the intradiscal side, when the molecule is inserted in the disk membrane. These mutations also affect amino acid residues that are wholly conserved in the human, mouse, rat, and bovine peripherin/RDS sequences. ${ }^{23}$ In addition, cosegregation of the R172W and F211L mutations with a retinitis pigmentosa disease phenotype has been shown. ${ }^{16-19}$

The $5289 \mathrm{~L}$ mutation affects a residue probably located on the cytoplasmic side of the membrane which, in contrast to the mutations above, is unique for the human sequence (A289 in the mouse, rat, and bovine sequences). The mutation could not be detected in any of the other 127 individuals tested and should thus be regarded as a rare sequence alteration. The lack of co-segregation of the mutation with the disease in the patient's family makes it possible that an alteration in a gene other than the peripherin/RDS gene is the disease causing event. Nevertheless, the fact that the family of the patient carrying the S289L mutation had a history of eye disease could mean that the S289L mutation is one of the mutations responsible for a digenic retinitis pigmentosa in which the other disease gene has not been identified yet. A digenic cause of retinitis pigmentosa has been reported, with concomitant mutations in the peripherin/RDS and ROM-1 genes found in affected individuals. ${ }^{24}$

In earlier studies, less than $5 \%$ of the autosomal dominant retinitis pigmentosa cases have been ascribed to mutations in the peripherin/RDS gene. ${ }^{45}$ However, in some of these studies, a part of the polymorphic region of the gene was not screened for mutations. Although our material is limited, our finding that at least three of 38 patients exhibited disease causing mutations indicates that peripherin/RDS gene defects might be more frequent than thought previously. Earlier reports have also indicated that mutations in the rhodopsin gene are more common in patients with autosomal dominant retinitis pigmentosa than peripherin/RDS gene mutations. For comparison, our earlier studies of the same patient group that was investigated here have revealed rhodopsin gene defects in only three of the 38 families. ${ }^{26-28}$

In conclusion, the DGGE screening described here has proved to be reliable and highly sensitive, making peripherin/RDS gene analysis by DGGE suitable as a routine procedure in the management of families with retinitis pigmentosa. Mutations in the peripherin/ RDS gene as the underlying cause of 
autosomal dominant retinitis pigmentosa seem to be at least as common among Swedish patients as in populations examined previously.

We thank G Nilsson for excellent technical assistance, Dr L S Lerman (Cambridge, Massachusetts, USA) for providing the computer programs MELT 07/87, and Dr S Bhattacharya and Dr T Dryja for kindly providing DNA with peripherin mutations. This work was supported in part by grants from the Physiographic Society of Lund the Medical Faculty Unive the Physiographic Society of Lund, the Medical Faculty, University of Lund, the Lund Medical Society, the Society for Swedish Medical Research Council (projects 04966 and 14X-2321).

1 Daiger SP, Sullivan LS, Rodriguez JA. Correlation of phenotype with genotype in inherited retinal degeneration. Behav Brain Sci 1995;18:452-67.

2 Dryja TP, McGee TL, Reichel E, et al. A point mutation of the rhodopsin gene in one form of retinitis pigmentosa. the rhodopsin gene in

3 Farrar GJ, Kenna P, Jordan SA, et al. A three-base-pair deletion in the peripherin-RDS gene in one form of retinitis tion in the peripherin-RDS gene in

4 Kajiwara K, Hahn LB, Mukai S, et al. Mutations in the human retinal degeneration slow gene in autosomal dominant retinitis pigmentosa. Nature 1991;354:480-3

5 Kajiwara K, Berson EL, Dryja TP. Digenic retinitis pigmentosa due to mutations at the unlinked peripherin/RDS and ROM1 loci. Science 1994;264:1604-8.

6 McLaughlin ME, Sandberg MA, Berson EL, et al. Recessive mutations in the gene encoding the $\beta$-subunit of rod phosphodiesterase in patients with retinitis pigmentosa. Nat Genet 1993;4:130-3.

7 Dryja TP, Finn JT, You-Wei P, et al. Mutations in the gene encoding the alfa subunit of the rod cGMP-gated channel in autosomal retinitis pigmentosa. Proc Natl Acad Sci USA 1995;92:10177-81

8 Huang SH, Pittler SJ, Huang X, et al. Autosomal recessive retinitis pigmentosa caused by mutations in the alfa subunit of rod cGMP phosphodiesterase. Nat Genet 1995;11: nit of rod

9 Myers RM, Sheffield VC, Cox DR. Detection of single base changes in DNA: ribonuclease cleavage and denaturing gradient gel electrophoresis. In: Davies KE, ed. Genome analysis, a practical approach. Oxford: IRL Press, 1988:95140.

10 Mullis KB, Faloona FA. Specific synthesis of DNA in vitro via polymerase catalyzed chain reaction. Methods Enzymo 1987;155:335-50

11 Sheffield VC, Cox DR, Lerman LS, et al. Attachment of a 40-base-pair G + C-rich sequence (GC-clamp) to genomic DNA fragments by the polymerase chain reaction result in improved detection of single-base changes. Proc Natl Acad Sci USA 1989;86:232-6.

12 Andréasson S, Ponjavic V, Ehinger B. Full-field electroretinogram in a patient with cutaneus melanomaassociated retinopathy. Acta Ophthalmol 1993;71:487-90.
13 Miller SA, Dykes DD, Polesky HF. A simple salting out procedure for extracting DNA from human nucleated cells. Nucleic Acids Res 1988;16:1215.

14 Sanger F, Nicklen S, Coulson AR. DNA sequencing with chain-terminating inhibitors. Proc Natl Acad Sci USA 1977;74:5463-7.

15 Jordan SA, Farrar GJ, Kenna P, et al. Polymorphic variation within "conserved" sequences at the 3 ' end of the human RDS gene which results in amino acid substitutions. Hum Mutat 1992;1:240-7.

16 Wroblewski JJ, Wells JA, Eckstein A, et al. Macular dystrophy associated with mutations at codon 172 in the human retinal degeneration slow gene. Ophthalmology 1994;101:12-22.

17 Reig C, Serra A, Gean E, et al. A point mutation in the RDS-peripherin gene in a Spanish family with central areolar choroidal dystrophy. Ophthalmic Genet 1995;16:39-44.

18 Piguet B, Héon E, Munier F L, et al. Full characterization of the maculopathy associated with an Arg-172-Trp mutation in the RDS/peripherin gene. Ophthalmic Genet 1996;17:4: 175-86.

19 Ekström U, Ponjavic V, Abrahamson M, et al. Phenotypic expression of autosomal dominant retinitis pigmentosa in a Swedish family expressing a Phe-211-Leu variant of peripherin/RDS. Ophthalmic Genet 1998;19:27-37.

20 Hayashi K, Yandell DW. How sensitive is PCR-SSCP? Hum Mutat 1993;2:338-46.

21 Abrams E, Stanton V Jr. Use of denaturing gradient gel electrophoresis to study conformational transitions in nucleic acids. Methods Enzymol 1992;212:71-104.

22 Nichols BE, Sheffield VC, Vandenburgh K, et al. Butterflyshaped pigment dystrophy of the fovea caused by a point mutation in codon 167 of the RDS gene. Nat Genet 1993; 3:202-7.

23 Travis GH, Christerson L, Danielson PE, et al. The human retinal degeneration slow (RDS) gene: chromosome assignment and structure of the mRNA. Genomics 1991;10:733-9.

24 Dryja TP, Hahn LB, Kajiwara K, et al. Dominant and digenic mutations in the peripherin/RDS and ROM1 genes in retinitis pigmentosa. Invest Ophthalmol Vis Sci 1997;38: 1972-82.

25 Wells J, Wroblewski J, Keen J, et al. Mutations in the human retinal degeneration slow (RDS) gene can cause either retinitis pigmentosa or macular dystrophy. Nat Genet 1993; 3:213-18.

26 Andréasson S, Ehinger B, Abrahamson M, et al. A six generation family with autosomal dominant retinitis pigmentosa and a rhodopsin gene defect (Arg-135-Leu). Ophthalmol Genet 1992;13:145-53.

27 Ponjavic V, Abrahamson M, Andréasson, et al. Autosomal dominant retinitis pigmentosa with rhodopsin mutation (Arg-135-Trp). Acta Ophthalmol Scand 1997;75:218-23.

28 Ponjavic V, Abrahamson M, Andréasson S, et al. A mild phenotype of autosomal dominant retinitis pigmentosa is associated with the rhodopsin mutation Pro-267-Leu. Ophthalmol Genet 1997;18:63-70.

\section{Fournal of Clinical Pathology - http://www.molpath.com}

Visitors to the world wide web can now access the fournal of Clinical Pathology either through the BMJ Publishing Group's home page (http://www.bmjpg.com) or directly by using its individual URL (http://www.molpath.com). There they will find the following:

- Current contents list for the journal

- Contents lists of previous issues

- Members of the editorial board

- Information for subscribers

- Instructions for authors

- Details of reprint services.

A hotlink gives access to:

- BMJ Publishing Group home page

- British Medical Association web site

- Online books catalogue

- BMJ Publishing Group books.

The web site is at a preliminary stage and there are plans to develop it into a more sophisticated site. Suggestions from visitors about features they would like to see are welcomed. They can be left via the opening page of the BMJ Publishing Group site or, alternatively, via the journal page, through "about this site". 